\title{
Reinforcement of health education and counselling by doctors in treatment and control of sexually transmitted disease
}

\author{
B O OGUNBANJO, M C ASUZU, E E EDET, AND A O OSOBA \\ From the Special Treatment Clinic, University College Hospital, Ibadan, Nigeria
}

SUMMARY The health education and medical counselling given by the social health worker to index patients with sexually transmitted disease (STD) attending our clinic were reinforced by a doctor attending a "treatment group" of patients in a randomised controlled trial.

Sixty four patients were randomised into two groups of 32 . Of the 96 follow up visits required for each group (three per patient), there were 20 defaults in the control group compared with only four in the patients whose health education had been reinforced by the doctor. Four of the control patients had been re-exposed to risk of infection during follow up compared with none in the reinforced group. Also five of the primary and none of the secondary sexual contacts of the control patients came for investigation and treatment (without the need for extra field contact tracing by the social worker) compared with eight primary and two secondary sexual contacts of the reinforced group.

The appreciable impact of counselling reinforcement by a doctor shown in this study leads us to emphasise the importance of this practice, especially in developing countries where various infrastructural and cultural factors usually make contact tracing an unrewarding exercise.

\section{Introduction}

The control of sexually transmitted disease (STD) has continued to pose serious problems for providers of health care all over the world. The emergence of newer problems, such as drug resistant organisms, is not making the problem any easier. Contact tracing strategies that have been shown to be beneficial in developed countries 12 are not readily applicable in developing countries. ${ }^{3}$ New strategies or methods to improve control are therefore needed, especially in developing countries. Our previous study in this centre shows that contact tracing by index patients is the most promising (if not the only) way of improving the result of contact tracing in this country. ${ }^{3}$ In view of these facts, and the noted effect of counselling reinforcement in improving compliance with desired social behaviour, ${ }^{4}$ this study was designed to see the effect, if any, of the attending doctor's reinforcement of the social worker's routine STD health education and medical counselling of index

Address for reprints: Dr B O Ogunbanjo, Department of Medical Microbiology, University College Hospital, Ibadan, Nigeria

Accepted for publication 9 May 1985 patients on their compliance with treatment instructions as well as their contribution to contact tracing.

\section{Patients, materials, and methods}

We randomly assigned 64 male patients treated for acute gonococcal urethritis into two groups, one receiving counselling reinforcement the other acting as a control group. Each group contained 32 patients. Demographic variables such as age, social class, and level of education did not differ appreciably between the two groups.

All the patients were seen, as is our normal practice, by the social worker who counselled them about STD as well as treatment and contact tracing. Without her knowledge, half the patients were given extra counselling and STD health education by a doctor. The counselling reinforcement covered three subjects: (1) the transmission and manifestations of STD, (2) the need for follow up visits and for following advice about treatment until the patient had been proved cured, and (3) the importance of bringing sexual contacts for treatment. All counselling reinforcement was given by the same doctor (BOO) to ensure standardisation. The extra 
time spent on each patient for this counselling was five to seven minutes.

Each patient attended for at least three follow up examinations until he was proved to have been cured. We recorded the attendance of the index patients for follow up, their re-exposure (if any) during follow up, and the response of their sexual contacts after the social worker had issued them with contact slips. We analysed these data to discover any differences that may have been attributable to counselling reinforcement.

\section{Results}

The table shows the results in relation to the three outcome variables. Of the 96 possible follow up visits in each group of patients (three per patient), there were 20 defaults in the control group compared with only four in the counselling reinforced group. The difference was significant $\left(Z_{c}=3 \cdot 27 ; p<0 \cdot 001\right)$. All four defaulters in the reinforcement group attended follow up later.

The number of patients re-exposed to risk and the number of sexual contacts who responded to the slip issued through the index patients showed similar results to those for follow up visits (in favour of the counselling reinforced group). Because of the limited numbers, however, the differences were not significant.

\section{Discussion}

Repetition is known to be useful in all learning processes, and reinforcement in health education has been noted to help the attainment of required social behaviour in education recipients. 4 The magnitude of this influence varies, however, and some reports have not shown such improved effects. In a study of American college students by Yarber, repeated STD education did not seem to influence current sexual attitudes, behaviour, or the acquisition of STD among the students. 5
The study published here, however, shows some remarkable benefits of such an exercise in this environment. This may be a phenomenon related to culture, but as our study provided personal counsel reinforcement, rather than the general impersonal "education" of the American study, both culture and the factor of the personal relationship between doctor and patient may have been at play here. In developing countries that lack infrastructural facilities for health work, contact tracing is inadequate, and the results are therefore poor. ${ }^{3}$ The findings of this study give grounds for every effort to be made to encourage doctors to counsel patients regularly. The same effect may, however, also be demonstrable in the technologically advanced countries.

Health education delivered by people held in high esteem is commonly thought to hold a greater chance of producing the desired healthy behaviour. 6 Epidemiological history taking and advice by a doctor have been postulated as likely to produce behaviour favourable for the desired control of STD. ${ }^{7}$ It is not surprising therefore, that after counselling by the doctor, many of our patients were willing to discuss their problems and asked more questions about STD. Some volunteered names or details of secondary contacts not previously mentioned in their history. It is thus obvious that the advantages of this form of patient counselling (by the doctor) in STD are many. Its practice and further evaluation are continuing at our clinic, and we recommend encouraging its practice in other STD clinics in developing countries where doctors are available and routinely manage such patients.

In health centres and rural areas where gross shortage of doctors leaves such patients under the care of nurses and paramedical staff, however, efforts should be directed at ensuring that such staff members are well trained (including training in the rudiments of health education and counselling) so that they can effectively give their patients health education.

TABLE Default from follow up, re-exposure to risk, and response of sexual contacts of index patients

\begin{tabular}{|c|c|c|c|}
\hline Variables of outcome & $\begin{array}{l}\text { Control } \\
\text { group } \\
(n=32)\end{array}$ & $\begin{array}{l}\text { Counselling } \\
\text { reinforcement } \\
\text { group }(n=32)\end{array}$ & Difference \\
\hline $\begin{array}{l}\text { No of defaults from follow up at: } \\
\text { First visit } \\
\text { Second visit } \\
\text { Third visit } \\
\text { Total defaults from follow up }\end{array}$ & $\begin{array}{r}8 \\
4 \\
8 \\
20\end{array}$ & $\begin{array}{l}0 \\
1 \\
3 \\
4\end{array}$ & $\mathrm{p}<0.001$ \\
\hline Re-exposure during follow up period & 4 & 0 & $\mathrm{p}<0.061$ \\
\hline $\begin{array}{l}\text { Responses of sexual contacts: } \\
\text { Primary contacts } \\
\text { Secondary contacts } \\
\text { Total sexual contacts }\end{array}$ & $\begin{array}{l}5 \\
0 \\
5\end{array}$ & $\begin{array}{r}8 \\
2 \\
10\end{array}$ & \\
\hline
\end{tabular}


We thank Mrs I O Ajayi, the social health sister, for her ready cooperation and help and to other members of staff of the special treatment clinic.

\section{References}

1. Harris JWR. The control of venereal diseases. British Journal of Venereal Diseases 1975;52:285-8.

2. Mills A, Satin A. Measuring the outcome of contact tracing. 2 . The responsibilities of the health worker and the outcome of contact investigations. British Journal of Venereal Diseases 1978;54:192-8.
3. Asuzu MC, Ogunbanjo BO, Ajayi IO, Oyediran ABOO, Osoba AO. Contact tracing in STD control in Ibadan. British Journal of Venereal Diseases 1984;60:114-6.

4. Hall JA, Roter DL, Rand CS. Communication of affect between patient and physician. J Health Soc Behav 1981;22: 18-30.

5. Yarber WL. Venereal disease education and a selected group of American college students. British Journal of Venereal Diseases 1977;53:58-62.

6. Lord Taylor of Harlow. The natural history of preventive medicine, or the breaking the chain of causation. $\mathrm{Br}$ Med $J$ 1980;281:849-53.

7. Felman YM, Nitkas JA. Obtaining history of patient's sexual activities. NY State J Med 1979;79:1879-81. 